\title{
ACCF/AHA 2007 Clinical Competence Statement on Vascular Imaging With Computed Tomography and Magnetic Resonance:
}

\author{
A Report of the American College of Cardiology Foundation/American Heart Association/
}

American College of Physicians Task Force on Clinical Competence and Training

Christopher M. Kramer, MD, FACC, FAHA[Chair], Matthew J. Budoff, MD, FACC, FAHA*, Zahi A. Fayad, PhD, FACC, FAHA ${ }^{\dagger}$, Victor A. Ferrari, MD, FACC, Corey Goldman, MD, PhD, FACP, FSVMB $\ddagger$, John R. Lesser, MD, FACC, Edward T. Martin, MD, FACC, FACP, FAHA, Sanjay Rajagopalan, MD, FACC $\$$, John P. Reilly, MD, FACC, FSCAIll, George P. Rodgers, MD, FACC, Lawrence Wechsler, MD, FAHA, Mark A. Creager, MD, FACC, FAHA[Chair], David R. Holmes Jr, MD, FACC, Geno Merli, MD, FACP, L. Kristin Newby, MD, FACC, FAHA,

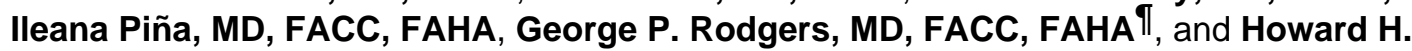
Weitz, MD, FACC, FACP

*Society of Cardiovascular Computed Tomography Representative

†Society of Atherosclerosis Imaging and Prevention Representative

¥Society for Vascular Medicine and Biology Representative

$\S$ Society for Cardiovascular Magnetic Resonance Representative

"Society for Cardiovascular Angiography and Interventions Representative

IFormer Task Force member during the writing effort

\section{Preamble}

The granting of clinical staff privileges to physicians is a primary mechanism used by institutions to uphold the quality of care. The Joint Commission on Accreditation of Healthcare Organizations requires that the granting of continuing medical staff privileges be based on assessments of applicants against professional criteria specified in the medical staff bylaws. Physicians themselves are thus charged with identifying the criteria that constitute professional competence and with evaluating their peers accordingly. Yet, the process of evaluating physicians' knowledge and competence is often constrained by the evaluator's own knowledge and ability to elicit the appropriate information, problems compounded by the growing number of highly specialized procedures for which privileges are requested.

The American College of Cardiology Foundation (ACCF)/American Heart Association (AHA)/ American College of Physicians (ACP) Task Force on Clinical Competence and Training was formed in 1998 to develop recommendations for attaining and maintaining the cognitive and technical skills necessary for the competent performance of a specific cardiovascular service, procedure, or technology. These documents are evidence-based, and where evidence is not

(C) 2007 by the American College of Cardiology Foundation and the American Heart Association, Inc.

Developed in Collaboration With the Society of Atherosclerosis Imaging and Prevention, the Society for Cardiovascular Angiography and Interventions, the Society of Cardiovascular Computed Tomography, the Society for Cardiovascular Magnetic Resonance, and the Society for Vascular Medicine and Biology

This document was approved by the American College of Cardiology Foundation Board of Trustees in June 2007 and by the American Heart Association Science Advisory and Coordinating Committee in July 2007. 
available, expert opinion is utilized to formulate recommendations. Indications and contraindications for specific services or procedures are not included in the scope of these documents. Recommendations are intended to assist those who must judge the competence of cardiovascular health care providers entering practice for the first time and/or those who are in practice and are undergoing periodic review of their practice expertise. The assessment of competence is complex and multidimensional; therefore, isolated recommendations contained herein may not necessarily be sufficient or appropriate for judging overall competence. The current document addresses competence in vascular imaging for computed tomography (CT) and magnetic resonance (MR) and is authored by representatives of the ACCF, the AHA, the Society of Atherosclerosis Imaging and Prevention (SAIP), the Society for Cardiovascular Angiography and Interventions (SCAI), the Society of Cardiovascular Computed Tomography (SCCT), the Society for Cardiovascular Magnetic Resonance (SCMR), and the Society for Vascular Medicine and Biology (SVMB).

The ACCF/AHA/ACP Task Force makes every effort to avoid any actual or potential conflicts of interest that might arise as a result of an outside relationship or a personal interest of a member of the ACCF/AHA/ACP Writing Committee. Specifically, all members of the Writing Committee are asked to provide disclosure statements of all such relationships that might be perceived as real or potential conflicts of interest relevant to the document topic. These are reviewed by the Writing Committee and updated as changes occur. The relationships with industry information for authors and peer reviewers are published in the appendices of the document.

\section{Introduction}

This statement is the first American College of Cardiology (ACC)/AHA document on clinical competence in vascular computed tomography (CT) and magnetic resonance imaging (MRI) and is designed to assist in the assessment of physicians' competence on a procedure-specific basis. The minimum experience, knowledge base, and technical skills necessary for the competent performance of vascular CT and MRI are specified. These represent the minimum experience requirements for the assessment of competence in these disciplines (or procedures) in the broadest sense. Whenever possible, the specifications are primarily based on consensus of expert opinion in the absence of extensive literature that links these factors with competence. The specifications are applicable to different practice settings and training backgrounds and can accommodate a number of ways in which physicians can demonstrate competence in the performance of specific procedures. Expertise in the performance of these procedures in patients with infrequently encountered diagnoses or of less commonly performed variations of standard procedures may require additional experience or training. Therefore, it is expected that even highly competent practitioners will occasionally benefit from consultation with colleagues who have even more highly specialized interests, experience, or skills. Due to the quantity and complexity of nonvascular findings that may be imaged with either technique, competence in imaging and interpretation of these findings is beyond the scope of this document.

This document addresses physicians who have already completed a formal training program and is not meant to encompass the training requirements for performing vascular MRI and $\mathrm{CT}$. The process of acquiring these skills is different once one has completed a formal training program. Training guidelines will be covered in the latest edition of Core Cardiology Training (COCATS) for cardiology trainees and in other documents put forth by other societies (1).

In addition to members of the ACCF and the AHA, the Writing Committee included representatives of the SAIP, the SCAI, the SCCT, the SCMR, and the SVMB.

Representation by an outside organization does not necessarily imply endorsement. In 
addition to content peer reviewers, "official" reviewers were provided by the ACC and the AHA. This document was approved for publication by the governing bodies of the ACC and the AHA. In addition, the governing boards from the SAIP, the SCAI, the SCCT, the SCMR, and the SVMB formally endorsed this document.

\section{Vascular CT}

\section{Cognitive Knowledge Required for Competency}

1. Hardware-Physicians interested in computed tomographic angiography (CTA) should have knowledge of advances in CT hardware (Table 1) which have accelerated since the introduction of axial CT in 1973. Starting with a rotating gantry incorporating an X-ray source, there have been progressive increases in the number of detector elements (2). Advances over the last decade include table translation simultaneous with rotation of a gantry incorporating an X-ray source with extended longitudinal or z-axis coverage. Thus, images can be reconstructed at any position along the patient axis (longitudinal or z-axis), and overlapping image reconstruction is used to improve longitudinal resolution (3). The introduction of 16-slice CT in 2003 marked the arrival of technology to assess all vascular territories including the lower extremities using detectors that were $0.75 \mathrm{~mm}$ or less in width. The 64-slice CT systems introduced in 2004 have resulted in further reductions in gantry rotation times to 330 to $420 \mathrm{~ms}$ and improved performance of electrocardiographic (ECG)-referenced scanning. Dual-source CT scanners introduced in 2006 further improve the temporal resolution of the ECG-referenced acquisition. A brief overview of the technical aspects of an multi-detector row computed tomography (MDCT) technology is included to facilitate understanding of the terms used in the subsequent sections of this report but is not intended to be comprehensive.

The MDCT design has evolved through successive iterations. In its simplest form, a modern MDCT scanner comprises an X-ray source, rotating gantry, pre- and post-detector collimators, and detector arrays. The detector assembly comprises several rows of detector elements that typically cover a scan field of view of approximately $50 \mathrm{~cm}$. The attenuation data (after passing from the source, through the body, and incident on the detector array) are recorded and transformed through filtered back-projection into the CT image. Axial or sequential scanning is the simplest and oldest technique for acquiring data. Helical/spiral scanning is characterized by continuous gantry rotation and continuous data acquisition while the patient table is moving at a constant speed.

2. Acquisition Techniques-Physicians must demonstrate competence in the techniques required in the acquisition and interpretation of a CTA exam. Specific acquisition techniques will be determined by the brand and capability of the scanner; a complete discussion is beyond the scope of this statement. In general, the region of interest for which the CTA has been requested and the scanner capacity will determine the scan acquisition parameters (4). Intravenous administration of an iodinated contrast medium must be synchronized with image acquisition. The volume, duration, and injection rate of contrast administration will be determined by the iodine concentration of the contrast and the duration of the scan (5). Physicians performing CTA must demonstrate an understanding of the factors that determine contrast transit times and the available means to accurately synchronize contrast administration and scanning. Candidates must understand the relative merits and limitations of both timing bolus and automated bolus monitoring techniques (6). Practitioners of CTA should understand the necessary adjustments in acquisition techniques for imaging pediatric patients, obese patients, patients that cannot raise their arms, and uncooperative patients.

3. Image Processing and Interpretation-MDCT acquires hundreds to thousands of axial images (7). Evaluation of the available source images is essential. The practitioner of 
CTA should also be comfortable with post-processing techniques which are performed at the computer workstation console. Arterial anatomy traverses multiple planes and, thus, cannot be completely displayed by axial or any other single projection. Multiplanar reformats (MPR) present the angiogram in two-dimensional (2D) planes. Curved multiplanar reformats (CMPR) trace a vessel through its contour and display the described axis through the vessel in a $2 \mathrm{D}$ plane. The CMPR is extremely useful for lumen measurement, thereby facilitating the detection of stenoses and measurement of aneurysms. As the interpreter defines the anatomy, both MPR and CMPR are subject to artifact if the true center of the vessel is incorrectly identified. Slab imaging allows the interpreter to evaluate the vessel lumen. Maximum intensity projection (MIP) displays the pixels with greatest Hounsfield value. Although MIPs may appear most similar to an invasive angiogram, calcification may preclude interpretation of vessel lumen; this format may underestimate and sometimes overestimate stenoses. Volume rendering (VR) displays the acquired data set as a threedimensional (3D) reconstruction. This technique accurately displays, in a readily identifiable manner, the course of vessels and surgical bypass grafts. It also easily demonstrates the relationship between vessels and extravascular structures. Physicians performing CTA must understand the diagnostic potential and limitations of each of the aforementioned interpretative techniques. They should also be able to recognize common artifacts including partial volume averaging or blooming artifacts from calcification and stents.

4. Contrast Agents-Aside from exposure to ionizing radiation, iodinated contrast material is the most significant risk of CTA. Contrast-induced nephropathy (CIN) is the third most common cause of acute renal failure among hospitalized patients (8). Physicians who wish to perform CTA must recognize that the presence of diabetes mellitus, preexisting renal insufficiency, congestive heart failure, and recent contrast exposure significantly increase the risk of CIN (9-11). Practitioners must understand measures that may offer some protection against CIN such as hydration, discontinuation of nephrotoxic drugs, and the use of nonionic, iso-osmolar contrast agents (12-15). Severe anaphylactic reactions to contrast material are seen in $0.04 \%$ to $0.22 \%$ of procedures and can be life threatening (16). Less severe allergic reactions are more commonly observed (17). Physicians performing CTA must be well acquainted with the treatment of cardiovascular collapse due to anaphylactic allergic reactions as well as to less severe reactions. They also must understand how to use prophylactic therapy prior to contrast administration in patients with a previous history of allergic response. They should consider a recommendation of alternative testing in those with a history of significant allergic reaction.

5. Radiation Dosimetry-Although ionizing radiation from natural sources is part of our daily existence, it is mandatory that practitioners of CTA understand the potential risks of ionizing radiation exposure from the test and balance these risks against the potential benefits. Health care professionals must have an understanding of the exposure involved in MDCT applications that image the vasculature and to effectively advise candidates for imaging. Patient doses for MDCT acquisition should be set at the lowest values that are consistent with satisfactory image quality. Most physicians seeking training in CTA applications will likely have had some didactic teaching regarding radiation physics during their training. However, specific instruction to keep radiation exposure as low as possible when performing MDCT may be additionally required. In general, there are differences in radiation exposure depending on the vascular application. Adoption of the effective dose as a standard measure of biologic risk allows comparability across the spectrum of medical and nonmedical exposures. The effective dose is, by definition, an estimate of the uniform, whole-body equivalent dose that would produce the same level of risk of adverse effects as from nonuniform partial body irradiation. The unit for the effective dose is the milliSievert (mSv) (www.fda.gov/cdrh/ct/rqu.html). Typical values for the effective patient dose of 
selected CT protocols are 1 to $2 \mathrm{mSv}$ for a head examination, 6 to $14 \mathrm{mSv}$ for noncoronary CTA of the chest, and 8 to $16 \mathrm{mSv}$ for CTA of the abdomen, pelvis, and lower extremities, depending on patient and scanner variables that may include dose-reduction strategies (1823). The effective dose of retrospective ECG-gated exams is much higher than that of nongated exams. This radiation exposure must be appreciated in the context of the average annual background radiation, which is 2 to $5 \mathrm{mSv}$ (average $=3.6 \mathrm{mSv}$ in the United States).

Axial/sequential techniques require less radiation and could be used for clinical indications that are least compromised by motion artifacts. In helical/spiral MDCT, which is more commonly used for chest angiography, the dose can be reduced by $30 \%$ to $50 \%$ by using ECG-controlled dose-modulation techniques. Another approach relevant to clinical practice is anatomic tube current modulation where the tube output is adapted to the patient geometry during each rotation of the scanner to compensate for strongly varying X-ray attenuations in asymmetric regions such as the shoulders and pelvis (24). The radiation dose increases with thinner slices (because tube current is typically increased to maintain image noise) and smaller pitch (more overlapping images). Another means to reduce radiation dose is to adapt the X-ray tube voltage to the intended application. Patient dose can be reduced by choosing lower $\mathrm{kVp}$ settings. A recent study reports a dose savings of $30 \%$ without a loss of diagnostic information with $100 \mathrm{kVp}$ when evaluating the aorta and iliac arteries (22). This approach, however, may not be appropriate for obese patients because penetration of X-rays decreases with decreasing tube voltage.

\section{Specific Applications}

A. AORTA: The practitioner of CTA should be knowledgeable about the utility of conventional CT scanning for diagnosing thoracic aortic aneurysms and dissections $(25,26)$. The knowledge required to perform aortic CTA includes the ability to diagnose aortic dissection, which can be identified with greater than 95\% accuracy. Excellent definition of the intimal flap, false and true lumens, and the amount of intra-aneurysmal thrombus can be determined. Practitioners of CTA should understand its use for diagnosing aortic aneurysm, defining its maximal diameter, and monitoring its expansion over time (27). Recognition of the use of CTA to diagnose traumatic aneurysms of the thoracic aorta, sinus of Valsalva aneurysms, and coarctation of the aorta is important. The diagnostician should understand the potential advantages of CTA in patients undergoing "redo" coronary artery bypass surgery (28). CTA may guide the surgical approach by defining the position of the sternum to the right ventricle, existing grafts, and aorta and thereby avoid unnecessary complications. The imager should recognize that the presence of severe aortic plaque raises the risk of stroke during "redo" surgery.

B. UPPER EXTREMITY ARTERIES: There is limited clinical data on the utility and performance of CTA for the diagnosis and management of upper extremity arterial disease $(29,30)$. CTA of upper extremity arterial disease requires knowledge of variant anatomy of the arch vessels including aberrant origins. Subclavian artery stenosis from a number of diseases, including atherosclerosis and vasculitis, can be effectively diagnosed using CTA. An understanding of the role of CTA in the diagnosis and management of subclavian and axillary aneurysms is essential. CTA allows accurate measurements of the diameter of the area to be treated as well as the length of the appropriate endograft. CTA can also be utilized for post-intervention surveillance to assess for endoleaks or deformity of the device.

Recognition of the etiology and anatomic location of the ischemic upper extremity is crucial to those who wish to practice CTA. Common causes include atherosclerotic disease, embolism (cardiac and vascular sources including thoracic outlet syndrome), and vasculitis. CTA can provide important information on the anatomy of the thoracic outlet; angiography with provocative maneuvers can be helpful in establishing the diagnosis. 
An understanding of the potential involvement of the upper extremity in up to $40 \%$ of extremity-penetrating trauma is important for CTA interpreters (31). Trauma can also result in vascular spasm, an intimal tear, pseudoaneurysm, arteriovenous fistula, or occlusion. CTA surveillance of hemodialysis access should be understood by those who perform the procedure. Because there is no concern for exacerbating renal dysfunction with iodinated contrast administration in hemodialysis patients, CTA offers a rapid, high spatial resolution study to assess graft patency and arterial inflow and venous outflow.

C. EXTRACRANIAL CEREBROVASCULAR ARTERIES: Practitioners should recognize that the use of CTA is rapidly increasing for vascular evaluation in patients with suspected cerebrovascular disease. CT is often the initial test in patients with transient ischemic attack (TIA) or stroke to exclude hemorrhage and to detect early changes associated with ischemia. CTA can be added to a CT examination, adding only 5 to $10 \mathrm{~min}$ to the study and providing real anatomic detail. CTA measurements of percent stenosis show a high correlation with digital subtraction angiography (DSA) (32) and in fact, 3D reconstructions of the carotid often permit a more complete assessment of eccentric lesions. An understanding that calcification interferes with CTA is crucial, particularly in complex calcified plaques where the degree of stenosis may not be adequately assessed. Segments of the carotid parallel to the plane of imaging are subject to flow effects, and stenosis of these regions may be artifactual. Knowledge of the strengths, weaknesses, and potential pitfalls of CTA imaging is essential to appropriate and accurate interpretation.

An understanding of the pathophysiological processes that affect the cerebral arteries is also important. Atherosclerosis is the most common cause of arterial narrowing and typically occurs at the carotid bifurcation in the neck, at the origin from the aortic arch, and in the intracranial segment at the level of the carotid siphon (33). Practitioners of CTA should be able to recognize other pathologies such as dissection, intraluminal thrombus, vasculitis, or vaso-spasm that may appear similar on CTA but should be distinguished by the clinical setting and anatomic characteristics. Knowledge of the clinical features of diseases that affect the cerebral circulation is necessary for optimal interpretation of CTA. In addition, recognition of symptoms attributable to the carotid and basilar circulation is important to focus interpretation on the clinically relevant arterial segments.

Knowledge of the different types of cerebral aneurysms is essential to physicians performing CTA, as CTA can readily define their size, length, and diameter. A thorough understanding of the appearance and distribution of arterial dissection is important to the proper identification and interpretation of CTA. Traumatic injury to the carotid artery commonly results in dissection. CTA practitioners should know that CTA may demonstrate a small irregular lumen even when other studies such as magnetic resonance angiography (MRA) or carotid ultrasound suggest occlusion $(34,35)$.

D. PELVIC AND LOWER LIMB ARTERIES: It should be understood that a complete acquisition of lower extremity inflow and run-off is presently available with MDCT angiography that was not previously available with fewer detectors (36). The increase in spatial resolution now afforded by CTA allows the differentiation between high- and lowgrade stenoses in peripheral vasculature, and the characterization of the nature of the lesion, differentiating atheromatous from thrombotic stenoses (37). CTA practitioners should understand that it has been shown to have excellent correlation with DSA (38-40). Limitations of CTA include the presence of dense calcifications and endoluminal stents, which may impair the quantification of the degrees of peripheral arterial disease (PAD).

Practitioners must demonstrate a thorough knowledge of arterial pathophysiology and its clinical presentation. Knowledge of just atherosclerotic disease is not sufficient. 
Competency also requires an understanding of inflammatory and aneurysmal diseases, thromboembolic disease, vascular injury, spontaneous and iatrogenic dissections, and congenital abnormalities. The capacity of CTA to visualize the arterial wall, as well as the lumen, provides the interpreter a greater degree of certainty when arriving at less common diagnoses. The relationship and effect of other anatomic structures on the vasculature must be understood, such as compression of venous structures by pelvic tumors resulting in stasis and thrombosis or dynamic compression of an entrapped popliteal artery. Knowledge of the potential utility of CTA in the evaluation of graft patency is important as well as in the detection of graft-related complications (graft stenosis, aneurysmal changes, and arteriovenous fistulas). Practitioners of CTA should recognize the value of CTA in the setting of peripheral vascular trauma in the assessment of complicated or partial occlusions, arteriovenous fistulae, intimal flaps, and pseudoaneurysms (31).

E. RENAL ARTERIES: The knowledge required to perform CTA of the renal arteries includes an understanding of the normal anatomy and its common variations such as accessory renal branches and familiarity with vascular anomalies and the usual location and appearance of a transplanted kidney (41). The diagnostician should be cognizant of the various etiologies of renal artery stenosis, including atherosclerosis, fibromuscular dysplasia, and other causes of renovascular disease such as polyarteritis nodosa, arteriovenous fistulae, aneurysms, thrombosis, and embolism. Identification of renal parenchymal enhancement patterns identifying the cortex, medulla, and the collecting system is important for the recognition of intrinsic parenchymal disease. The interpreter should be capable of relating renal CTA findings with results of other diagnostic imaging modalities, particularly duplex ultrasonography and MRA.

F. MESENTERIC ARTERIES: CTA of the mesenteric arteries requires knowledge of the normal anatomy of the celiac artery, superior mesenteric artery, and inferior mesenteric artery as well as the common variants and collaterals such as pancreaticoduodenal collaterization and the marginal artery of Drummond, a collateral vessel to the superior mesenteric artery. The expert should be cognizant of the etiologies and pathophysiology of mesenteric ischemia such as atherosclerosis, arterial thrombosis or embolism, vasculitis, celiac trunk compression from the median arcuate ligament, and mesenteric vein thrombosis (41). The CTA specialist should recognize the clinical manifestations of mesenteric ischemia and be knowledgeable about the indications for endovascular and surgical therapies for both acute and chronic mesenteric ischemia.

G. CT VENOGRAPHY: The practitioner of CTA should understand the use of peripheral venous CT for demonstrating deep venous thrombosis (DVT), especially the proximal extent into the iliac vein or inferior vena cava (IVC) (42). CT venography provides direct imaging of the IVC, pelvic and lower extremity veins immediately after CT of the pulmonary arteries without injection of additional contrast material, adding only a few minutes to the examination. The diagnostician should be aware that because DVT is the most important factor predisposing to pulmonary embolism (PE), a single examination capable of evaluating both the pulmonary arterial system and the pelvic and lower extremity venous system may offer advantages over other tests directed at either diagnosis alone (43). Practitioners should understand that adding CT venography to CTA increases the sensitivity for PE without reducing specificity (44).

Knowledge of the use of CT venography in the evaluation of venous thrombosis involving the upper extremity veins (brachiocephalic and axillary veins) is important, especially in cases of suspected venous thrombosis due to malignancies (Malignant Superior Vena Cava Syndrome) (45). Owing to the superior discriminatory properties of CT for lung parenchyma over MRI, CT venography in conjunction with CT of the chest is the diagnostic study of 
choice for this type of evaluation. The expert should be capable of identifying venous contrast mixing artifacts commonly seen in standard renal CTA in relation to discerning renal vein thrombosis. The limitations of CTA for identifying mesenteric venous thrombosis should be appreciated, and the predicted locations of mesenteric and portal veins should be included in the expert's knowledge base.

H. OTHER: The previous list is not meant to be exhaustive. There may be other organspecific applications, such as arteriovenous malformations, which are not specifically addressed.

\section{Formal Training and Competence in Vascular CT}

There are several potential pathways to achieve competence in vascular CT, including formal fellowship pathways and alternative pathways. The training achieved may allow a practitioner to either interpret or, depending on the expertise achieved, interpret and teach others the competencies in vascular CT. Cognitive skills required to demonstrate competence in vascular CTA are summarized in Table 2. All trainees will be required to demonstrate competence in the theoretical principles of CT imaging using MDCT technology. Candidates should receive didactic lectures from a qualified CT-trained physician and/or physicist on the basic physics of CT in general and of MDCT in particular. A thorough understanding of contrast injection methods, adverse events and their treatments, and contrast kinetics in patients will be required. In particular, knowledge is needed in appropriate bolus timing approaches that may be different for various vascular beds.

For those in cardiology fellowship training programs, specific training in vascular anatomy and physiology through dedicated vascular medicine training within the fellowship would be required. A thorough knowledge and understanding of vascular anatomy is required.

Knowledge of characteristics of blood vessels in health and disease by traditional angiographic imaging methods (X-ray contrast angiography) provide a conceptual framework for application to CTA of the peripheral vessels. Basic concepts in vessel physiology are vital for an angiographer interpreting a stenosis in any vascular bed and basic training should be part of any formal training program.

1. Formal Fellowship_Formal training in vascular CT may be undertaken as part of cardiovascular fellowship (see the latest COCATS guidelines for cardiovascular computed tomography $[\mathrm{CCT}]$ ) (1). The didactic training experience achieved should parallel that described in the COCATS recommendations for Level 2 trainees. Trainees should actively participate in daily CT study interpretation under the direction of a Level 2 or 3 (preferred) CCT-qualified physician. For all studies in which other vascular imaging data are available, such information should be correlated with $\mathrm{CT}$ data. This should include at least 50 cases of vascular $\mathrm{CT}$, for which the trainee is present during the scan, ideally as the primary operator and the primary interpreter.

2. Alternative Pathways—Potential alternative pathways include spending at least 4 weeks with a practitioner of vascular CT who has the prior experience to train such an individual (Table 3). For those individuals who have achieved Level 2 or 3 training in cardiac $\mathrm{CT}$, there is no specific time requirement. With either pathway, at least 50 cases of vascular CT should be performed to demonstrate competence, ideally for which the trainee is present during the scan and is the primary operator/interpreter. These cases should include the variety of cases as previously outlined. An additional 100 cases from teaching files, case studies, CDs/DVDs, or continuing medical education (CME) courses should also be reviewed. 


\section{Maintaining Expertise in Vascular CT}

As is true for many other procedures, a minimum number of cases are necessary to ensure continued proficiency in quality of care.

1. Clinical Experience-Maintenance of vascular $\mathrm{CT}$ expertise requires both ongoing $\mathrm{CME}$ and regular performance and interpretation of vascular CT examinations. Physicians should periodically attend postgraduate courses and workshops that focus on vascular CT, especially those that emphasize new and evolving techniques and developments. In addition, physicians should seek to compare the quality, completeness, and results of their own examinations with those presented at scientific meetings and in professional publications. If competence is assured primarily on the basis of continuing experience, a minimum of 50 examinations per year is recommended in order to maintain the physician's skills. Because a physician's practice or location may preclude this method, continued competency can also be assured through monitoring and evaluation that indicates acceptable technical success, accuracy of interpretation, and appropriateness of evaluation.

2. CME-Thirty hours of category I CME over 3 years in CCT or related fields are required to maintain expertise in vascular $\mathrm{CT}$ regardless of pathway.

\section{Vascular MR}

\section{Cognitive Knowledge Required for Competency}

1. Hardware and General Principles of MR-A brief overview of the technical aspects of cardiovascular magnetic resonance (CMR) as it applies to evaluation of blood vessels is included to facilitate the understanding of terms used in the subsequent sections of this report and is not intended to be comprehensive. The practitioner of vascular MR should comprehend the general principles of MR. Hardware used in an MR scanner are listed in Table 4.

The phenomenon of MR is restricted to atomic nuclei with unpaired spin such as hydrogen atoms (protons). In the presence of an external magnetic field, the hydrogen nucleus acts like a small magnet and aligns itself parallel to an external field, precessing about its axis in a manner analogous to a spinning top. The frequency of precession for hydrogen is 42.58 $\mathrm{MHz} / \mathrm{T}$, which corresponds to $63 \mathrm{MHz}$ at a field strength of $1.5 \mathrm{~T}$ and $128 \mathrm{MHz}$ at $3 \mathrm{~T}$, and is in the radiofrequency (RF) range. Hydrogen nuclei can be excited by radio waves only at this resonant frequency (Larmor Frequency), which has the effect of rotating the net magnetization vector by an amount termed the "flip angle." After this excitation, the net magnetization returns to its former position (relaxation) during which energy is transmitted as a radio signal and can be detected by a receiver coil. The return of the net magnetization vector to equilibrium has 2 components. The vector component parallel to the main field relatively slowly returns to equilibrium by interacting with surrounding molecules; this is known as "T1 relaxation." Recovery of the vector component transverse to the field is more rapid and is termed "T2 relaxation." The CMR images can be weighted to T1, T2, or proton density in order to derive signal differences that are intrinsic to the tissue and help characterize the latter. In order to localize the signals coming from the body, gradient magnetic fields of varying magnitude (phase-encoding steps) are switched on and off at appropriate times required to spatially encode MR signal. An MR pulse sequence is a combination of RF pulses and magnetic gradient field alterations controlled by the scanning computer.

To speed up image acquisition, parallel imaging techniques have been developed. These are based on an optimal utilization of redundant information from multiple phased-array coils 
and allow a reduction in the time-consuming phase-encoding steps required to spatially encode MR signal. High spatial resolution images can be acquired in a markedly shortened time (often by a factor of 2 to 4). Parallel imaging is a mainstay of modern MRA and is used in conjunction with a variety of techniques including contrast-enhanced magnetic resonance angiography (CE-MRA), where it allows rapid imaging during peak arterial contrast opacification. Potential limitations include a reduction in the signal-to-noise ratio.

2. Acquisition Techniques-Knowledge of MRA techniques is essential to the practitioner of MRA. This brief summary outlines the major techniques that the diagnostician should understand. MRA has evolved rapidly since its introduction more than 15 years ago. Initially, non-CE-MRA techniques found their way into clinical routine for imaging vascular morphology. These early approaches can in principle be divided into 2 subgroups (i.e., "black blood" and "bright blood" sequences). Although black blood techniques based on signal voids within vessels containing flowing spins can confirm vessel patency, they remain of limited use in the assessment of vascular morphology. They are currently gaining acceptance, however, for the evaluation of the vascular wall (46).

Bright blood MRA techniques are generally divided into those influenced by the effect of blood flow on signal (time of flight, or TOF) and those based on the flow effect on phase (phase contrast, or PC). Advantages of TOF include a strong signal from blood and that it is completely noninvasive (no contrast agents are needed). However, acquisition times are relatively long, and spin dephasing in areas of flow turbulence results in signal loss that may lead to stenosis overestimation. PC angiography derives image contrast from the differences in the phases accumulated by stationary and moving spins in a magnetic field gradient. The amount of phase accumulated is directly proportional to the flow velocity, allowing quantitative measurement of flow velocities and the discrimination of flow direction. The flow dependence and associated artifacts inherent to these techniques have restricted their clinical use primarily to the extracranial and intracranial arterial system and the portal venous system.

With the advent of high-performance gradient systems, newer MRA strategies have been developed for CE-MRA using gadolinium chelates (47). Intravenous gadolinium chelates are the most commonly employed contrast agents in clinical practice. MRA is based on the combination of rapid 3D imaging and the T1-shortening effect of intravenously infused paramagnetic contrast. These agents greatly shorten the $\mathrm{T} 1$ of blood resulting in very bright signal intensity in T1-weighted images. Data acquisition needs to be precisely timed to the arterial phase of the contrast when intraluminal signal is maximal, and be fast enough to minimize motion artifacts and to avoid venous contamination that may hamper image interpretation. Advantages of CE-MRA over older TOF techniques include higher signal-tonoise ratios, robustness irrespective of blood flow patterns or velocities, and faster image acquisition, allowing for the evaluation of larger anatomic segments (from the aortic arch to the circle of Willis). As variants of CE-MRA, time-resolved techniques enable the dynamic visualization of contrast transit through the vasculature and are not dependent on the precise timing of the acquisition, although at the cost of lower spatial resolution. These techniques have been proven to give an extensive and diagnostically accurate evaluation of extracranial, thoracic, abdominal, and peripheral vessels. In many centers, 3D CE-MRA has widely replaced conventional X-ray angiography for the clarification of pathologies in arterial vessels (48).

3. Image Processing and Interpretation-The practitioner of MRA should be knowledgeable about post-processing techniques that are performed at the computer workstation console. Post-processing should include evaluation of the source images from the MRA as well as reformatted images, such as MPR. Image subtraction may be performed 
and MIPs using thick and/or thin slabs encompassing each vascular territory of interest may be viewed for the purposes of diagnosis. Interpreters should comprehend post-processing of PC images to calculate flows in various vascular beds. Practitioners should be aware of artifacts, such as pseudostenoses, created by metallic devices (e.g., stents and clips).

4. MRA Contrast-MRA is usually performed with $3 \mathrm{D}$ coverage of the vessel during a short breath-hold and after intravenous injection of a gadolinium-based contrast agent. Gadolinium has 7 unpaired electrons in its outer shell and hastens T1 relaxation, thereby increasing signal in the area of interest. Gadolinium alone is cytotoxic, but not when combined with a chelating agent. Gadolinium has similar pharmacokinetic properties to iodinated X-ray contrast but with minimal nephrotoxicity and anaphylaxis risk. Several Food and Drug Administration (FDA)-approved gadolinium preparations have been used for over a decade and the safety profile is far more favorable than iodinated contrast. A study of high-dose gadolinium in a population with a high prevalence of baseline renal insufficiency showed no renal failure associated with its administration (49). The rate of allergic reactions to gadolinium is also very low. A survey of 105 centers with more than 700,000 patients receiving the contrast agent has been performed (50). The rate of adverse reactions was very low and was limited to mild nausea, vomiting, and urticaria. The rate of serious allergic reactions was less than $0.01 \%(50)$.

On May 23, 2007, the FDA updated a previously issued public health advisory (51) after receiving 90 reports of patients with at least moderate renal dysfunction, gadolinium exposure, and subsequent development of nephrogenic systemic fibrosis (NSF), a dermatologic condition that is characterized by severe and progressive skin induration (52). The proposed association between gadolinium and NSF is strengthened by recent reports of gadolinium isolated from biopsy specimens up to 11 months post-administration in patients with NSF (53). The updated FDA advisory states that exposure to gadolinium-based contrast agents increases the risk for NSF in patients with acute or chronic severe renal insufficiency (glomerular filtration rate less than $30 \mathrm{~mL} / \mathrm{min} / 1.73 \mathrm{~m}^{2}$ ) or acute renal insufficiency of any severity due to the hepato-renal syndrome or in the perioperative liver transplantation period. The risk, if any, for developing NSF among patients with mild to moderate renal insufficiency or normal renal function is unknown. When recommending or performing an MRI or MRA, carefully weigh the benefits and risks associated with using a gadoliniumbased contrast agent in light of recent reports of NSF/nephrogenic fibrosing dermopahy observed following administration of these agents. Choose an alternative imaging method and/or contrast agent whenever possible. 2) Although there are no published data to determine the utility of dialysis to prevent or treat NSF/nephrogenic fibrosing dermopahy, consider prompt dialysis of patients with moderate to end-stage renal disease who undergo an MRI or MRA with a gadolinium-based contrast agent.

5. MRI Safety-MRI is very safe with no short- or long-term ill effects at current field strengths (less than or equal to $3 \mathrm{~T}$ ). Claustrophobia is problematic in $3 \%$ to $7 \%$ of patients. A very important safety issue for CMR is the prevention of ferromagnetic objects from entering the scanner area as these will become projectiles. Metallic implants such as hip prostheses, mechanical heart valves, coronary stents, and sternal sutures present no hazard since the materials used are not ferromagnetic (although a local image artifact will result). Care is required in patients with cerebrovascular clips as certain older models remain unsafe in the MR environment. Electronic implants (i.e., infusion or monitoring devices, neurostimulation devices) are still considered absolute contraindications. Pacemakers and implanted cardioverter-defibrillators are considered a contraindication, although recently there have been several case series of patients with pacemakers who successfully underwent MR scanning at $1.5 \mathrm{~T}$ with very few changes in pacer function (54-56). This is an area of active investigation and MR-compatible devices are in development. 


\section{Specific Applications}

A. AORTA: An understanding of the utility of MRA in diseases of the aorta is essential. MRA is an excellent technique to define the overall size, shape, and extent of aortic aneurysms. MRI has excellent sensitivity and specificity for the determination of a presence of dissection, and it can cover large fields of view, permitting full assessment of its extent $(57,58)$. It should be recognized that MRI offers certain advantages in aortic dissection, including the ability to characterize thrombus or slow flow in the false lumen by exploiting differences in signal properties. Multiplanar noncontrast imaging can also help delineate intramural hematoma. Practitioners of MRA should know how to use MRI and MRA to demonstrate the characteristic features of penetrating atherosclerotic ulcers (59). MRA of aortic coarctation requires the ability to recognize the site of narrowing, involvement of branch vessels, and the extent of collateral vessels (60). Diagnosticians should understand the use of PC MRI techniques to measure the velocities and flow proximal and distal to the narrowed segments, and estimate the degree of stenosis and the amount of collateral flow (61).

B. UPPER EXTREMITY ARTERIES: Clinical competence in MRA requires an understanding of its use in the assessment of abnormalities of the brachiocephalic, subclavian, and axillary arteries. Interpreters of MRA should understand that atherosclerosis is the cause of the majority of stenotic and aneurysmal disease in the arteries of the upper extremities (62) and that MRA is quite accurate in its diagnostic capacity in this regard (63). Practitioners of MRA should recognize "subclavian steal syndrome" and the ability to depict reversal of flow by PC MRA or TOF MRA with a presaturation pulse first above and then below the vertebral artery (64) as well as the use of CE-MRA to depict the precise site of anatomic obstruction (65). A knowledge of the use of multiple MR techniques in the evaluation of inflammatory arteritis (66) is essential (e.g., Takayasu's arteritis which has a predeliction for involvement of the aortic arch vessels). MRA can demonstrate evidence of giant cell arteritis that can lead to stenoses or aneurysmal dilation in the thoracic aorta and subclavian and axillary arteries. MR can be useful in the diagnosis of thoracic outlet syndrome as MRI during arm abduction and adduction may confirm vascular compression (67). A competent interpreter of MR of the arterial branches of the aortic arch should be able to recognize and evaluate congenital anomalies such as a vascular ring may cause tracheal or esophageal compression. MRA is an excellent test for evaluation of the arch. Diagnosticians should be familiar with volumetric interpolated breath-hold examination imaging (68) after gadolinium, which can clearly demonstrate the relationship of the trachea, esophagus, and arch vessels.

C. EXTRACRANIAL CEREBROVASCULAR ARTERIES: Knowledge of the signs and symptoms of cerebrovascular disease, common syndromes attributable to specific arterial segments and pathophysiology of stroke are essential elements to the interpretation of MRA. A thorough understanding of cerebrovascular MRA is crucial as it has become an integral part of the routine evaluation for cerebral ischemia. As MRI is used frequently in stroke, MRA can be included with only a few minutes of added scan time. The intracranial carotid artery is easily demonstrated with MRA, and gadolinium-enhanced MRA allows imaging of the entire circulation from the aortic arch to the first division of the major intracranial arteries. 3D reconstructions result in an excellent view of eccentric or highly focal lesions that are not always apparent on the usual anteroposterior and lateral views.

Interpretation of MRA requires a detailed knowledge of the anatomy of the cerebral circulation as well as an understanding of the strengths and weaknesses of vascular imaging with MR in order to interpret normal and abnormal findings. A number of artifacts occur with MRA, and physicians involved in interpretation must understand these pitfalls. Due to 
the dephasing effects of turbulence, MRA may overestimate the severity of stenosis. MRA is highly specific but identification of significant stenoses generally requires confirmation by another technique. Horizontal segments of the carotid artery, such as the intracranial segment, are less well visualized because of dephasing in the horizontal plane and, thus, a diagnosis of stenosis in this plane is not always reliable. The addition of cerebral MR perfusion contributes complementary information and together with MRA can improve understanding of the clinical significance of arterial lesions.

Physicians interpreting MRA should know that its accuracy is similar to that of CTA for detecting intracranial cerebral aneurysms (69). Sensitivity is greater for larger aneurysms and falls precipitously for aneurysms less than $5 \mathrm{~mm}$. Physicians interpreting MRA should be aware of the difficulty detecting small aneurysms as well as common sites of infundibulums and branch points that can be confused with aneurysms. Pitfalls of MRA, including the effects of movement, turbulence, and slow flow, should be considered. Knowledge of the common sites of aneurysms is important for optimal recognition. Physicians should be well-versed in the use of T1- and T2-weighted and fat-suppressed MRI as well as MRA to detect carotid dissection. It should be recognized that vertebral dissection is not as reliably identified. Knowledge of the use of MRA to detect arterial injury, particularly dissection, is critical in the evaluation of patients with trauma.

D. PELVIC AND LOWER LIMB ARTERIES: A thorough knowledge of techniques employed in peripheral MRA is essential. CE-MRA using a multistation bolus-chase technique in conjunction with dedicated peripheral phased-array coils and extended field of view imaging $(500 \mathrm{~mm})$ allow scanning from the diaphragm to the pedal vessels in 3 stations. The addition of parallel imaging technologies, along with novel $\mathrm{k}$-space reordering schemes, especially in the distal stations, has made peripheral runoff MRA significantly more robust, with fewer failed studies and with vastly improved image quality (submillimeter isotropic voxels at the distal stations) (70). Diagnosticians should be cognizant of techniques to reduce venous contamination in the distal stations by the use of centric k-spaced ordered schemes for data acquisition in the distal stations, along with biphasic administration of gadolinium, with a reduced rate of injection for the second bolus (48). The use of venous compression devices at the level of the thighs (with pressures set to less than or equal to $50 \mathrm{~mm} \mathrm{Hg}$ ) also has been shown to delay venous filling (71). The additional incorporation of a time resolved MRA or a dedicated 3D data set at the level of the calf, typically performed prior to a traditional multi-station 3D MRA acquisition, has been shown to result in images devoid of venous contamination and of excellent diagnostic quality (72,73). Physicians should recognize the high sensitivity and specificity of MRA for the diagnosis of PAD (74) and the utility of MRA for assessing graft patency, as well as inflow and outflow disease (75).

Practitioners of vascular MR should understand the use of additional vessel wall-specific sequences used in conjunction with MRA, particularly in the abdomen, which may help delineate aneurysms, presence of intramural clot, dissection, and atherosclerosis with only a minimal increase in scan time. Sequences that may be chosen for this purpose include darkblood half Fourier acquisition single-shot turbo spin-echo images, fat-saturated volumetric $\mathrm{T} 1$ gradient echo sequence, or a traditional inversion recovery prepared gradient echo sequence, especially after contrast.

E. RENAL ARTERIES: Practitioners of MR should appreciate that renal artery stenosis is an important cause of secondary hypertension. The knowledge required to perform renal MRA includes an understanding of its ability to evaluate the renal arteries and accessory renal arteries directly (76), establish the site and severity of stenoses, and their hemodynamic significance (77), measure kidney size and parenchymal thickness, and 
identify perirenal and aortic pathology. The specialist should be able to recognize and identify the causes of renal artery stenosis, which include atherosclerotic disease, fibromuscular dysplasia, arterial dissection, and extrinsic compression of renal arteries. Aneurysms involving the main renal arteries should be identified; however, the smaller intraparenchymal aneurysms seen in polyarteritis nodosa may not be as reliably detected. Physicians should comprehend the pulse sequences used to assess the renal arteries including 2D or 3D TOF, PC imaging, and CE-MRA. The use of contrast allows for a more accurate evaluation of tortuous vessels, distal vessels, and smaller accessory renal arteries and can aid in the diagnosis of fibromuscular dysplasia. The MRA interpreters should have knowledge of the use of the technique in renal donors or after renal transplantation. The expert should be able to use post-processing techniques including subvolume MIPs encompassing each renal artery in coronal, oblique, and axial planes (78).

F. MESENTERIC ARTERIES: Physicians should recognize that unlike acute mesenteric ischemia, chronic mesenteric ischemia due to atherosclerotic disease is well-suited for evaluation by MRA. Knowledge of the appropriate pulse sequence to use for this disorder is essential. Although TOF (79) and PC MRA (80) can be used, CE-MRA is more robust and faster, especially when parallel imaging techniques are applied $(47,81)$. The CEMRA techniques are highly accurate and compare favorably to catheter-based approaches (82). The specialist should also be able to recognize normal anatomy and its variations as well as surgical anatomy. The causes of acute and chronic mesenteric ischemia need to be recognized and specific etiologies such as atherosclerosis, arterial and venous thrombosis, external compression, and vasculitis should be identified. The specialist should also be able to identify pseudostenosis and aneurysmal disease. Practitioners of MRA should be able to recognize anatomic variations and celiac artery pseudostenosis, which is commonly caused by extrinsic compression by the median arcuate ligament. MRA can also be useful for evaluation after a revascularization procedure and for examining the extent and nature of external compression on mesenteric arteries or veins.

G. MR VENOGRAPHY: Knowledge of superior vena cava (SVC) and IVC anatomy, as well as potential causes of compression or obstruction (tumor, thrombus, etc.), is essential to the interpreter of MRA (83). It is important to recognize benign systemic venous anomalies such as a persistent left SVC with or without azygous continuation of the IVC (84). In the cerebral circulation, knowledge of typical clinical syndromes of venous infarction and the imaging characteristics of venous infarcts that distinguish them from arterial disease is essential to proper interpretation. MR venography visualizes the major venous sinuses and detailed knowledge of venous anatomy is necessary to identify occlusive disease associated with infarction. Physicians should have knowledge of common congenital variants that might be misinterpreted as a pathological venous occlusion. They should understand that mesenteric venous occlusion is an uncommon but important cause of mesenteric ischemia. Practitioners of MRA should understand the potential of multiphase dynamic CE imaging (85) for examination of the venous system.

H. WHOLE BODY MRA: There is a known relationship between the presence of significant stenoses in one vascular bed with asymptomatic disease in another (86). Thus, practitioners of MRA should appreciate whole body MRA as a potential screening tool. This has been performed by combining the bolus-chase approach with a rolling table platform (87). Knowledge of techniques to optimize whole body MRA is important including the use of integrated parallel acquisition techniques to increase spatial and temporal resolution and reduce venous contamination in the abdomen and infrapopliteal region, without an increase in acquisition time (88). However, the clinical value of whole body MRA has not yet been systematically tested in large populations. 


\section{Formal Training to Achieve Competence}

Cognitive skills required to demonstrate competence in vascular MR are summarized in Table 5. The physician should be able to demonstrate competence in the theoretical principles of MRI. Trainees should receive didactic lectures from a qualified MR-trained physician and/or physicist on the basic physics of MR. A thorough understanding of contrast injection methods and contrast kinetics in patients will be required. In particular, knowledge is needed in appropriate bolus timing approaches that may be different for various vascular beds. A thorough knowledge and understanding of vascular anatomy is required. Characteristics of a vessel in health and disease by traditional angiographic imaging methods (X-ray contrast angiography) will provide a significant background for application to MRA of the peripheral vessels. An understanding of basic concepts in vessel physiology is vital for an angiographer interpreting a stenosis in any vascular bed and basic training should be part of any formal training program.

There are several potential pathways to achieve competence in vascular MR including formal fellowships and alternative pathways, both with accompanying CME. The training achieved may allow a practitioner to either interpret or, depending on the expertise achieved, interpret and teach others the competencies in vascular MR. Table 5 lists the cognitive skills required for competence in vascular MR.

1. Formal Fellowship-Formal training in vascular MR may be undertaken as part of cardiovascular fellowship (see the latest COCATS guidelines for CMR) (1). The didactic training experience achieved should parallel that described in the COCATS guidelines for Level 2 trainees. A basic understanding of MR physics and clinical applications should be obtained. Trainees should actively participate in daily MR study interpretation under the direction of a Level 2 or 3 (preferred) CMR-qualified physician. For all studies in which other vascular imaging data are available, such information should be correlated with MR data. This should include at least 50 cases of vascular MR, for which the trainee is present during the scan, ideally as the primary operator and the primary interpreter.

2. Alternative Pathways-Alternative pathways (Table 6) include at least 4 weeks spent with a practitioner of vascular MR who has the prior training experience. For those individuals who have achieved Level 2 or 3 training in CMR, there is no specific time requirement. With either pathway, at least 50 cases of vascular MR should be performed to demonstrate competence, ideally for which the trainee is present during the scan and is the primary operator/interpreter. These cases should include the variety of cases as previously outlined. An additional 100 cases from teaching files, case studies, CDs/DVDs, or CME courses also should be reviewed.

\section{Maintaining Expertise}

As is true for many other procedures, a minimum number of cases are necessary to ensure continued proficiency in quality of care.

1. Clinical Experience-Maintenance of vascular MR expertise requires both ongoing $\mathrm{CME}$ and regular performance and interpretation of vascular MR examinations. Physicians should periodically attend postgraduate courses and workshops that focus on vascular MR, especially those that emphasize new and evolving techniques and developments. In addition, physicians should seek to compare the quality, completeness, and results of their own examinations with those presented at scientific meetings and in professional publications. If competence is assured primarily on the basis of continuing experience, a minimum of 50 examinations per year is recommended in order to maintain the physician's skills. Because a physician's practice or location may preclude this method, continued competency can also be 
assured through monitoring and evaluation that indicates acceptable technical success, accuracy of interpretation, and appropriateness of evaluation.

2. CME-Thirty hours of CME over 3 years in CMR or related fields are required to maintain expertise in vascular MR.

\section{APPENDIX 1}




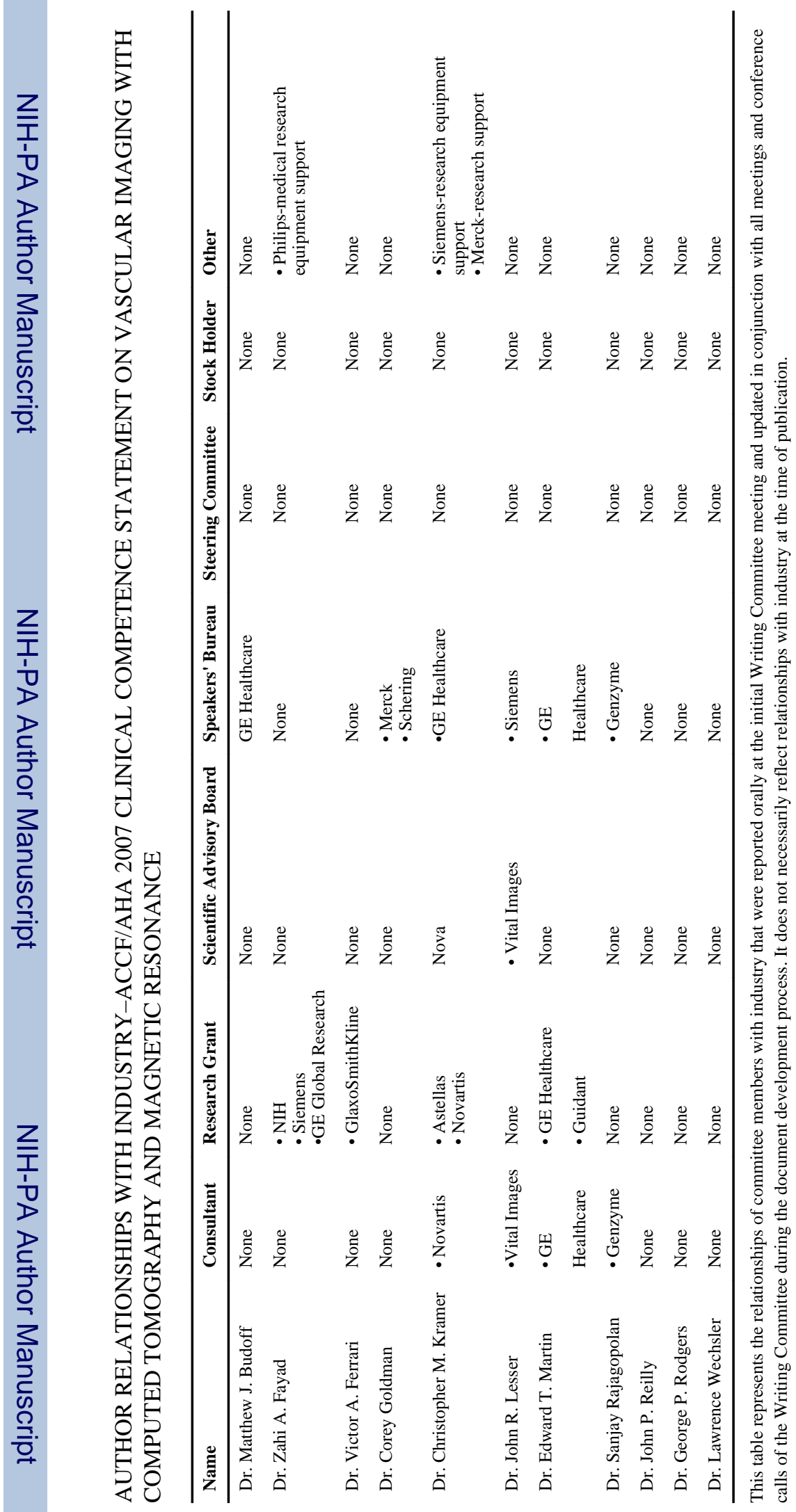




\section{APPENDIX 2}




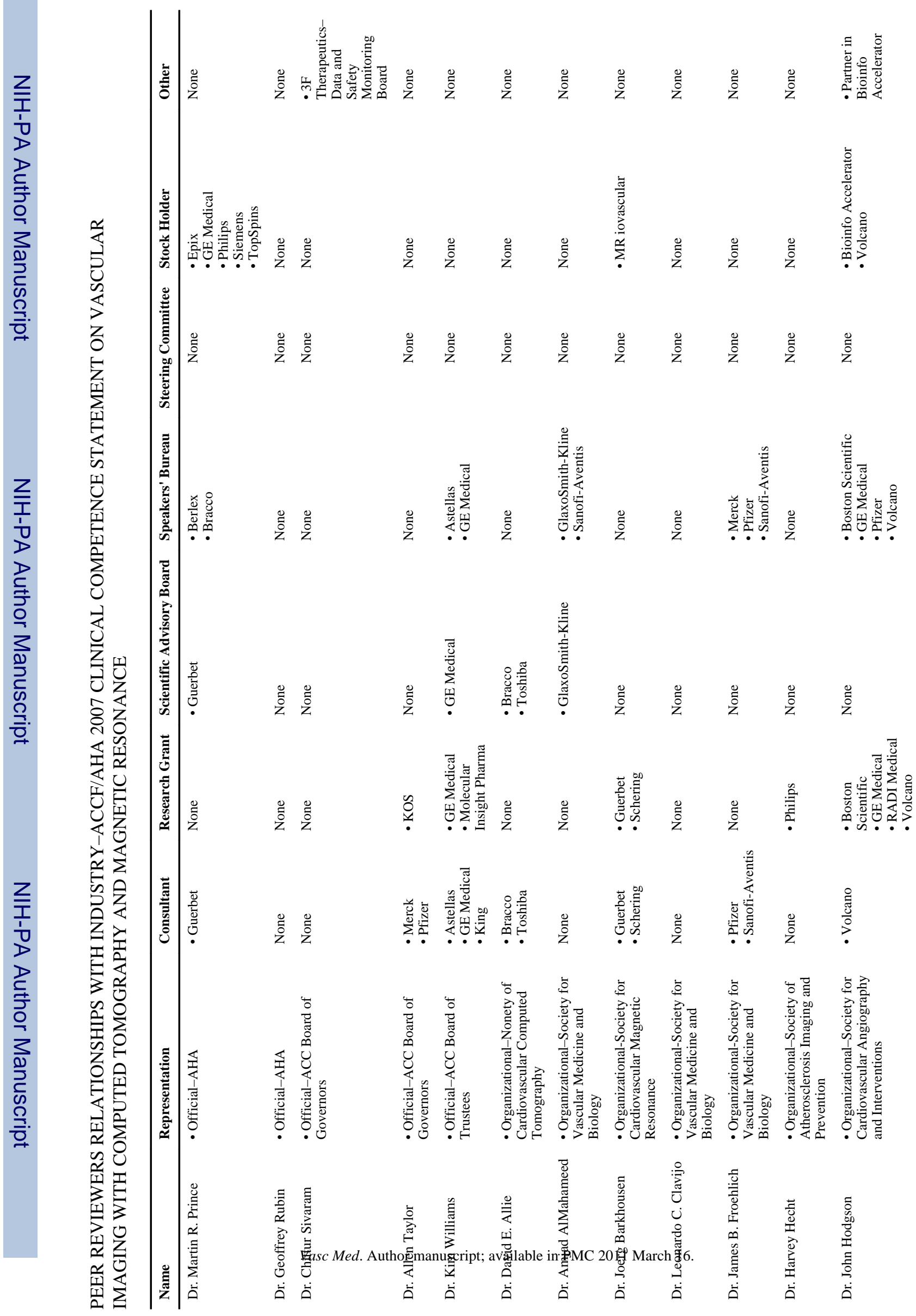




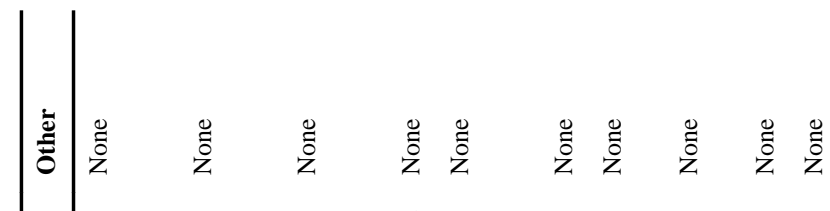

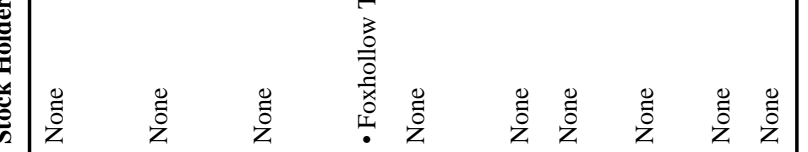

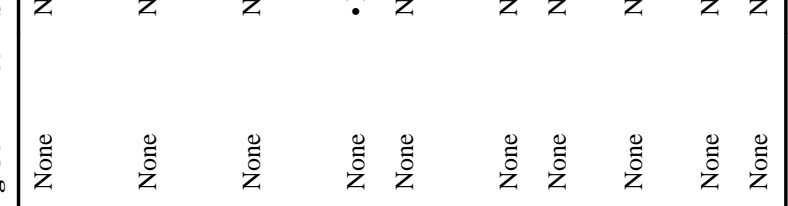

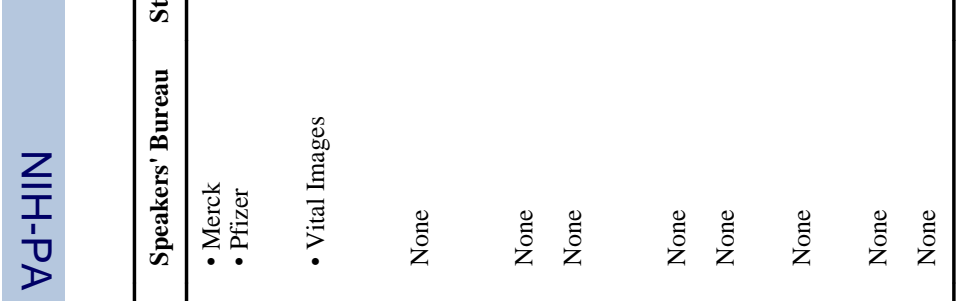



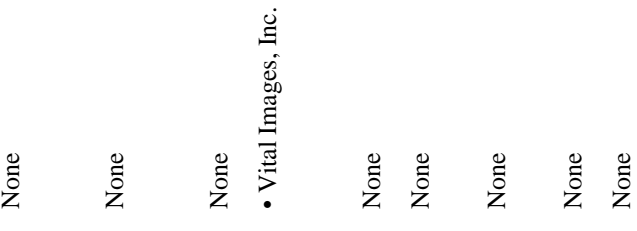

$\begin{array}{lllll} & & & \\ & & & \\ 0\end{array}$ 


\section{REFERENCES}

1. Beller GA, Bonow RO, Fuster V. ACC revised recommendations for training in adult cardiovascular medicine. 2007 update of the Core Cardiology Training 3 (COCATS 3)_full revision. J Am Coll Cardiol. 2007 In press.

2. Kalender WA, Seissler W, Klotz E, Vock P. Spiral volumetric CT with single-breath-hold technique, continuous transport, and continuous scanner rotation. Radiology. 1990; 176:181-3. [PubMed: 2353088]

3. Flohr TG, Schaller S, Stierstorfer K, Bruder H, Ohnesorge BM, Schoepf UJ. Multi-detector row CT systems and image-reconstruction techniques. Radiology. 2005; 235:756-73. [PubMed: 15833981]

4. Chow LC, Rubin GD. CT angiography of the arterial system. Radiol Clin North Am. 2002; 40:72949. [PubMed: 12171182]

5. Fleischmann D. Present and future trends in multiple detector-row CT applications: CT angiography. Eur Radiol. 2002; 12(Suppl 2):S11-5. [PubMed: 12232656]

6. Fleischmann D, Hallett RL, Rubin GD. CT angiography of peripheral arterial disease. J Vasc Interv Radiol. 2006; 17:3-26. [PubMed: 16415129]

7. Rubin GD. Data explosion: the challenge of multidetector-row CT. Eur J Radiol. 2000; 36:74-80. [PubMed: 11116170]

8. Nash K, Hafeez A, Hou S. Hospital-acquired renal insufficiency. Am J Kidney Dis. 2002; 39:930-6. [PubMed: 11979336]

9. McCullough PA, Wolyn R, Rocher LL, Levin RN, O'Neill WW. Acute renal failure after coronary intervention: incidence, risk factors, and relationship to mortality. Am J Med. 1997; 103:368-75. [PubMed: 9375704]

10. Mehran R, Aymong ED, Nikolsky E, et al. A simple risk score for prediction of contrast-induced nephropathy after percutaneous coronary intervention: development and initial validation. J Am Coll Cardiol. 2004; 44:1393-9. [PubMed: 15464318]

11. Rudnick MR, Goldfarb S, Wexler L, et al. Nephrotoxicity of ionic and nonionic contrast media in 1196 patients: a randomized trial. The Iohexol Cooperative Study. Kidney Int. 1995; 47:254-61. [PubMed: 7731155]

12. Aspelin P, Aubry P, Fransson SG, Strasser R, Willenbrock R, Lundkvist J. Cost-effectiveness of iodixanol in patients at high risk of contrast-induced nephropathy. Am Heart J. 2005; 149:298303. [PubMed: 15846268]

13. Chalmers N, Jackson RW. Comparison of iodixanol and iohexol in renal impairment. Br J Radiol. 1999; 72:701-3. [PubMed: 10624328]

14. Merten GJ, Burgess WP, Gray LV, et al. Prevention of contrast-induced nephropathy with sodium bicarbonate: a randomized controlled trial. JAMA. 2004; 291:2328-34. [PubMed: 15150204]

15. Schweiger MJ, Chambers CE, Davidson CJ, et al. Prevention of contrast induced nephropathy: recommendations for the high risk patient undergoing cardiovascular procedures. Cathet Cardiovasc Interv. 2007; 69:135-40.

16. Katayama H, Yamaguchi K, Kozuka T, Takashima T, Seez P, Matsuura K. Adverse reactions to ionic and nonionic contrast media. A report from the Japanese Committee on the Safety of Contrast Media. Radiology. 1990; 175:621-8. [PubMed: 2343107]

17. Shehadi WH. Contrast media adverse reactions: occurrence, recurrence, and distribution patterns. Radiology. 1982; 143:11-7. [PubMed: 7063711]

18. Kuiper JW, Geleijns J, Matheijssen NA, Teeuwisse W, Pattynama PM. Radiation exposure of multi-row detector spiral computed tomography of the pulmonary arteries: comparison with digital subtraction pulmonary angiography. Eur Radiol. 2003; 13:1496-500. [PubMed: 12835959]

19. Mastora I, Remy-Jardin M, Delannoy V, et al. Multi-detector row spiral CT angiography of the thoracic outlet: dose reduction with anatomically adapted online tube current modulation and preset dose savings. Radiology. 2004; 230:116-24. [PubMed: 14645883]

20. Tack D, De Maertelaer, V, Petit W, et al. Multi-detector row CT pulmonary angiography: comparison of standard-dose and simulated low-dose techniques. Radiology. 2005; 236:318-25. [PubMed: 15987983] 
21. Fraioli F, Catalano C, Napoli A, et al. Low-dose multidetector-row CT angiography of the infrarenal aorta and lower extremity vessels: image quality and diagnostic accuracy in comparison with standard DSA. Eur Radiol. 2006; 16:137-46. [PubMed: 15988586]

22. Wintersperger B, Jakobs T, Herzog P, et al. Aorto-iliac multidetector-row CT angiography with low kV settings: improved vessel enhancement and simultaneous reduction of radiation dose. Eur Radiol. 2005; 15:334-41. [PubMed: 15611872]

23. Willmann JK, Baumert B, Schertler T, et al. Aortoiliac and lower extremity arteries assessed with 16-detector row CT angiography: prospective comparison with digital subtraction angiography. Radiology. 2005; 236:1083-93. [PubMed: 16055691]

24. Kalender WA, Wolf H, Suess C, Gies M, Greess H, Bautz WA. Dose reduction in CT by on-line tube current control: principles and validation on phantoms and cadavers. Eur Radiol. 1999; 9:323-8. [PubMed: 10101657]

25. Nienaber CA, von Kodolitsch Y, Nicolas V, et al. The diagnosis of thoracic aortic dissection by noninvasive imaging procedures. N Engl J Med. 1993; 328:1-9. [PubMed: 8416265]

26. Sommer T, Fehske W, Holzknecht N, et al. Aortic dissection: a comparative study of diagnosis with spiral CT, multiplanar transesophageal echocardiography, and MR imaging. Radiology. 1996; 199:347-52. [PubMed: 8668776]

27. Stanford W, Rooholamini SA, Galvin JR. Ultrafast computed tomography in the diagnosis of aortic aneurysms and dissections. J Thorac Imaging. 1990; 5:32-9. [PubMed: 2258988]

28. Schlosser T, Konorza T, Hunold P, Kuhl H, Schmermund A, Barkhausen J. Noninvasive visualization of coronary artery bypass grafts using 16-detector row computed tomography. J Am Coll Cardiol. 2004; 44:1224-9. [PubMed: 15364323]

29. Ye C, Mao Z, Rong S, et al. Multislice computed tomographic angiography in evaluating dysfunction of the vascular access in hemodialysis patients. Nephron Clin Prac. 2006; 104:c94100.

30. Hellinger JC, Fleischmann D, Rubin GD. Evaluating upper extremity arterial disease with multidetector-row CT Angiography. Experience in 40 examinations (abstr). J Vasc Interv Radiol. 2005; 16:S59.

31. Soto JA, Munera F, Morales C, et al. Focal arterial injuries of the proximal extremities: helical CT arteriography as the initial method of diagnosis. Radiology. 2001; 218:188-94. [PubMed: 11152800]

32. Josephson SA, Bryant SO, Mak HK, Johnston SC, Dillon WP, Smith WS. Evaluation of carotid stenosis using CT angiography in the initial evaluation of stroke and TIA. Neurology. 2004; 63:457-60. [PubMed: 15304575]

33. Fisher, CM. The anatomy and pathology of the cerebral vasculature. In: Meyer, JS., editor. Modern Concepts of Cerebrovascular Disease. Spectrum; Holliswood, NY: 1975. p. 1-41.

34. Koelemay MJ, Nederkoorn PJ, Reitsma JB, Majoie CB. Systematic review of computed tomographic angiography for assessment of carotid artery disease. Stroke. 2004; 35:2306-12. [PubMed: 15345798]

35. Bash S, Villablanca JP, Jahan R, et al. Intracranial vascular stenosis and occlusive disease: evaluation with CT angiography, MR angiography, and digital subtraction angiography. AJNR Am J Neuroradiol. 2005; 26:1012-21. [PubMed: 15891154]

36. Jakobs TF, Wintersperger BJ, Becker CR. MDCT-imaging of peripheral arterial disease. Semin Ultrasound CT MR. 2004; 25:145-55. [PubMed: 15160795]

37. Boll DT, Lewin JS, Duerk JL, Smith D, Subramanyan K, Merkle EM. Assessment of automatic vessel tracking techniques in preoperative planning of transluminal aortic stent graft implantation. J Comput Assist Tomogr. 2004; 28:278-85. [PubMed: 15091135]

38. Catalano C, Napoli A, Fraioli F, Venditti F, Votta V, Passariello R. Multidetector-row CT angiography of the infrarenal aortic and lower extremities arterial disease. Eur Radiol. 2003; 13(Suppl 5):M88-93. [PubMed: 14989616]

39. Martin ML, Tay KH, Flak B, et al. Multidetector CT angiography of the aortoiliac system and lower extremities: a prospective comparison with digital subtraction angiography. AJR Am J Roentgenol. 2003; 180:1085-91. [PubMed: 12646460] 
40. Rubin GD, Schmidt AJ, Logan LJ, Sofilos MC. Multi-detector row CT angiography of lower extremity arterial inflow and runoff: initial experience. Radiology. 2001; 221:146-58. [PubMed: 11568333]

41. Fleischmann D. MDCT of renal and mesenteric vessels. Eur Radiol. 2003; 13(Suppl 5):M94-101. [PubMed: 14989617]

42. Reimer P, Landwehr P. Non-invasive vascular imaging of peripheral vessels. Eur Radiol. 1998; 8:858-72. [PubMed: 9683688]

43. Kanne JP, Lalani TA. Role of computed tomography and magnetic resonance imaging for deep venous thrombosis and pulmonary embolism. Circulation. 2004; 109:I15-21. [PubMed: 15051664]

44. Stein PD, Fowler SE, Goodman LR, et al. Multidetector computed tomography for acute pulmonary embolism. N Engl J Med. 2006; 354:2317-27. [PubMed: 16738268]

45. Eren S, Karaman A, Okur A. The superior vena cava syndrome caused by malignant disease. Imaging with multi-detector row CT. Eur J Radiol. 2006; 59:93-103. [PubMed: 16476534]

46. Choudhury RP, Fuster V, Fayad ZA. Molecular, cellular and functional imaging of atherothrombosis. Nat Rev Drug Discov. 2004; 3:913-25. [PubMed: 15520814]

47. Prince MR. Gadolinium-enhanced MR aortography. Radiology. 1994; 191:155-64. [PubMed: 8134563]

48. Carroll TJ, Grist TM. Technical developments in MR angiography. Radiol Clin North Am. 2002; 40:921-51. [PubMed: 12171192]

49. Prince MR, Arnoldus C, Frisoli JK. Nephrotoxicity of high-dose gadolinium compared with iodinated contrast. J Magn Reson Imaging. 1996; 6:162-6. [PubMed: 8851422]

50. Murphy KP, Szopinski KT, Cohan RH, Mermillod B, Ellis JH. Occurrence of adverse reactions to gadolinium-based contrast material and management of patients at increased risk: a survey of the American Society of Neuroradiology Fellowship Directors. Acad Radiol. 1999; 6:656-64. [PubMed: 10894068]

51. U.S. Food and Drug Administration Information for Health Professionals. Gadolinium-based contrast agents for magnetic resonance imaging (marketed as Magnevist, MultiHance, Omniscan, Opti-MARK, ProHance). [Accessed July 24, 2007]. Available at: http://www.fda.gov/cder/drug/InfoSheets/HCP/gcca_200705HCP.pdf. Last update May 23, 2007.

52. Mendoza FA, Artlett CM, Sandorfi N, Latinis K, Piera-Velazquez S, Jimenez SA. Description of 12 cases of nephrogenic fibrosing dermopathy and review of the literature. Semin Arthritis Rheum. 2006; 35:238-49. [PubMed: 16461069]

53. Kuo PH, Kanal E, bu-Alfa AK, Cowper SE. Gadolinium-based MR contrast agents and nephrogenic systemic fibrosis. Radiology. 2007; 242:647-9. [PubMed: 17213364]

54. Martin ET, Coman JA, Shellock FG, Pulling CC, Fair R, Jenkins K. Magnetic resonance imaging and cardiac pacemaker safety at 1.5-Tesla. J Am Coll Cardiol. 2004; 43:1315-24. [PubMed: 15063447]

55. Nazarian S, Roguin A, Zviman MM, et al. Clinical utility and safety of a protocol for noncardiac and cardiac magnetic resonance imaging of patients with permanent pacemakers and implantablecardioverter defibrillators at 1.5 tesla. Circulation. 2006; 114:1277-84. [PubMed: 16966586]

56. Sommer T, Naehle CP, Yang A, et al. Strategy for safe performance of extrathoracic magnetic resonance imaging at 1.5 tesla in the presence of cardiac pacemakers in non-pacemaker-dependent patients: a prospective study with 115 examinations. Circulation. 2006; 114:1285-92. [PubMed: 16966587]

57. Moore AG, Eagle KA, Bruckman D, et al. Choice of computed tomography, transesophageal echocardiography, magnetic resonance imaging, and aortography in acute aortic dissection: International Registry of Acute Aortic Dissection (IRAD). Am J Cardiol. 2002; 89:1235-8. [PubMed: 12008187]

58. Pereles FS, McCarthy RM, Baskaran V, et al. Thoracic aortic dissection and aneurysm: evaluation with nonenhanced true FISP MR angiography in less than 4 minutes. Radiology. 2002; 223:270-4. [PubMed: 11930077] 
59. Macura KJ, Szarf G, Fishman EK, Bluemke DA. Role of computed tomography and magnetic resonance imaging in assessment of acute aortic syndromes. Semin Ultrasound CT MR. 2003; 24:232-54. [PubMed: 12954006]

60. Gutberlet M, Hosten N, Vogel M, et al. Quantification of morphologic and hemodynamic severity of coarctation of the aorta by magnetic resonance imaging. Cardiol Young. 2001; 11:512-20. [PubMed: 11727906]

61. Mohiaddin RH, Kilner PJ, Rees S, Longmore DB. Magnetic resonance volume flow and jet velocity mapping in aortic coarctation. J Am Coll Cardiol. 1993; 22:1515-21. [PubMed: 8227813]

62. Wu C, Zhang J, Ladner CJ, Babb JS, Lamparello PJ, Krinsky GA. Subclavian steal syndrome: diagnosis with perfusion metrics from contrast-enhanced MR angiographic bolus-timing examination—initial experience. Radiology. 2005; 235:927-33. [PubMed: 15845794]

63. Randoux B, Marro B, Koskas F, Chiras J, Dormont D, Marsault C. Proximal great vessels of aortic arch: comparison of three-dimensional gadolinium-enhanced MR angiography and digital subtraction angiography. Radiology. 2003; 229:697-702. [PubMed: 14563902]

64. Drutman J, Gyorke A, Davis WL, Turski PA. Evaluation of subclavian steal with two-dimensional phase-contrast and two-dimensional time-of-flight MR angiography. AJNR Am J Neuroradiol. 1994; 15:1642-5. [PubMed: 7847207]

65. Van Grimberge F, Dymarkowski S, Budts W, Bogaert J. Role of magnetic resonance in the diagnosis of subclavian steal syndrome. J Magn Reson Imaging. 2000; 12:339-42. [PubMed: 10931598]

66. Atalay MK, Bluemke DA. Magnetic resonance imaging of large vessel vasculitis. Curr Opin Rheumatol. 2001; 13:41-7. [PubMed: 11148714]

67. Panegyres PK, Moore N, Gibson R, Rushworth G, Donaghy M. Thoracic outlet syndromes and magnetic resonance imaging. Brain. 1993; 116:823-41. [PubMed: 8394773]

68. Keogan MT, Edelman RR. Technologic advances in abdominal MR imaging. Radiology. 2001; 220:310-20. [PubMed: 11477231]

69. White PM, Wardlaw JM, Easton V. Can noninvasive imaging accurately depict intracranial aneurysms? A systematic review. Radiology. 2000; 217:361-70. [PubMed: 11058629]

70. Bezooijen R, van den Bosch HC, Tielbeek AV, et al. Peripheral arterial disease: sensitivityencoded multiposition MR angiography compared with intraarterial angiography and conventional multiposition MR angiography. Radiology. 2004; 231:263-71. [PubMed: 15068952]

71. Vogt FM, Ajaj W, Hunold P, et al. Venous compression at high-spatial-resolution threedimensional MR angiography of peripheral arteries. Radiology. 2004; 233:913-20. [PubMed: 15486208]

72. Meissner OA, Rieger J, Weber C, et al. Critical limb ischemia: hybrid MR angiography compared with DSA. Radiology. 2005; 235:308-18. [PubMed: 15716387]

73. Zhang HL, Khilnani NM, Prince MR, et al. Diagnostic accuracy of time-resolved 2D projection MR angiography for symptomatic infrapopliteal arterial occlusive disease. AJR Am J Roentgenol. 2005; 184:938-47. [PubMed: 15728621]

74. Koelemay MJ, Lijmer JG, Stoker J, Legemate DA, Bossuyt PM. Magnetic resonance angiography for the evaluation of lower extremity arterial disease: a meta-analysis. JAMA. 2001; 285:1338-45. [PubMed: 11255390]

75. Jackson MJ, Bicknell CD, Zervas V, et al. Three-dimensional reconstruction of autologous vein bypass graft distal anastomoses imaged with magnetic resonance: clinical and research applications. J Vasc Surg. 2003; 38:621-5. [PubMed: 12947290]

76. Bakker J, Beek FJ, Beutler JJ, et al. Renal artery stenosis and accessory renal arteries: accuracy of detection and visualization with gadolinium-enhanced breath-hold MR angiography. Radiology. 1998; 207:497-504. [PubMed: 9577501]

77. Schoenberg SO, Knopp MV, Londy F, et al. Morphologic and functional magnetic resonance imaging of renal artery stenosis: a multireader tricenter study. J Am Soc Nephrol. 2002; 13:15869. [PubMed: 11752033]

78. Dong Q, Schoenberg SO, Carlos RC, et al. Diagnosis of renal vascular disease with MR angiography. Radiographics. 1999; 19:1535-54. [PubMed: 10555673] 
79. Miyazaki T, Yamashita Y, Shinzato J, Kojima A, Takahashi M. Two-dimensional time-of-flight magnetic resonance angiography in the coronal plane for abdominal disease: its usefulness and comparison with conventional angiography. Br J Radiol. 1995; 68:351-7. [PubMed: 7795969]

80. Wasser MN, Geelkerken RH, Kouwenhoven M, et al. Systolically gated 3D phase contrast MRA of mesenteric arteries in suspected mesenteric ischemia. J Comput Assist Tomogr. 1996; 20:2628. [PubMed: 8606234]

81. Meaney JF, Prince MR, Nostrant TT, Stanley JC. Gadolinium-enhanced MR angiography of visceral arteries in patients with suspected chronic mesenteric ischemia. J Magn Reson Imaging. 1997; 7:171-6. [PubMed: 9039611]

82. Carlos RC, Stanley JC, Stafford-Johnson D, Prince MR. Interobserver variability in the evaluation of chronic mesenteric ischemia with gadolinium-enhanced MR angiography. Acad Radiol. 2001; 8:879-87. [PubMed: 11724043]

83. Kee ST, Kinoshita L, Razavi MK, Nyman UR, Semba CP, Dake MD. Superior vena cava syndrome: treatment with catheter-directed thrombolysis and endovascular stent placement. Radiology. 1998; 206:187-93. [PubMed: 9423671]

84. White CS, Baffa JM, Haney PJ, Pace ME, Campbell AB. MR imaging of congenital anomalies of the thoracic veins. Radiographics. 1997; 17:595-608. [PubMed: 9153699]

85. Bradbury MS, Kavanagh PV, Bechtold RE, et al. Mesenteric venous thrombosis: diagnosis and noninvasive imaging. Radiographics. 2002; 22:527-41. [PubMed: 12006685]

86. Herborn CU, Goyen M, Quick HH, et al. Whole-body 3D MR angiography of patients with peripheral arterial occlusive disease. AJR Am J Roentgenol. 2004; 182:1427-34. [PubMed: 15149986]

87. Goyen M, Quick HH, Debatin JF, et al. Whole-body three-dimensional MR angiography with a rolling table platform: initial clinical experience. Radiology. 2002; 224:270-7. [PubMed: 12091695]

88. Fenchel M, Scheule AM, Stauder NI, et al. Atherosclerotic disease: whole-body cardiovascular imaging with MR system with 32 receiver channels and total-body surface coil technology-initial clinical results. Radiology. 2006; 238:280-91. [PubMed: 16304083] 
Table 1

CT Hardware

\begin{tabular}{ll}
\hline CT Hardware & Details \\
\hline $\begin{array}{l}\text { X-ray tube and focal } \\
\text { spot }\end{array}$ & $\begin{array}{l}\text { Usually consists of a cathode from which electrons are emitted onto a spot on the anode (focal-spot) resulting in a } \\
\text { generation of X-rays. Some manufacturers allow dynamic deflection of the electron beam striking the anode along the } \\
\text { Z-axis ("flying focal spot"). Both tube current (mA) and voltage (kVp) are adjustable parameters. } \\
\text { X-ray tube and detector array are mounted opposite each other on a rotating gantry capable of withstanding high } \\
\text { gravitational forces. }\end{array}$ \\
Gantry & $\begin{array}{l}\text { Located between X-ray tube and patient and is used to shape the beam along the longitudinal (z) axis. The opening } \\
\text { (beam collimation) is adjusted according to the selected slice width and the size/position of focal spot. }\end{array}$ \\
Tube collimator & $\begin{array}{l}\text { Comprise solid-state elements that convert X-ray into light impulses, and photodiodes, which convert the light into an } \\
\text { electrical signal. A fixed array detector consists of detector elements with equal sizes in the } \mathrm{z} \text { direction, while an } \\
\text { adaptive array has detectors of different widths. }\end{array}$ \\
& $\begin{array}{l}\text { Equal to table feed per rotation (mm)/total width of the collimated beam. For ECG-referenced vascular applications, a } \\
\text { pitch of } 0.2 \text { to } 0.4 \text { is required, while higher pitches (greater than } 1.0) \text { may suffice for nongated vascular applications. }\end{array}$ \\
\hline Pitch &
\end{tabular}

$\mathrm{CT}=$ computed tomography $; \mathrm{ECG}=$ electrocardiogram. 
Table 2

\section{Cognitive Skills Required for Competence in Vascular CT}

\begin{tabular}{|c|c|}
\hline Knowledge & Cognitive Skills \\
\hline \multirow[t]{5}{*}{ General } & Physics of CT and radiation generation and exposure \\
\hline & Scanning principles and scanning modes for noncontrast- and contrast-enhanced vascular imaging \\
\hline & Principles of intravenous iodinated contrast administration for safe and optimal vascular imaging \\
\hline & Prevention, recognition, and treatment of adverse reactions to iodinated contrast \\
\hline & Principles of image post-processing and appropriate applications \\
\hline \multirow[t]{2}{*}{ Vascular anatomy } & $\begin{array}{l}\text { Normal anatomy of the aorta, brachiocephalic, cerebrovascular, pelvic and lower extremity, renal, and } \\
\text { mesenteric arteries }\end{array}$ \\
\hline & $\begin{array}{l}\text { Normal anatomy of the SVC and IVC, cerebrovascular, pelvic, lower extremity, renal, and mesenteric } \\
\text { veins }\end{array}$ \\
\hline \multirow[t]{2}{*}{ Vascular pathology } & $\begin{array}{l}\text { Congenital anomalies, aneurysm, dissection, occlusion, and stenosis, of the aorta, brachiocephalic, } \\
\text { cerebrovascular, pelvic and lower extremity, renal, and mesenteric arteries }\end{array}$ \\
\hline & $\begin{array}{l}\text { Thrombosis, compression, occlusion in and of the SVC and IVC, cerebrovascular, pelvic, lower } \\
\text { extremity, renal, and mesenteric veins }\end{array}$ \\
\hline $\begin{array}{l}\text { Symptoms and signs of disease } \\
\text { related to above vasular pathology }\end{array}$ & \\
\hline
\end{tabular}

$\mathrm{CT}=$ computed tomography IVC $=$ inferior vena cava SVC $=$ superior vena cava. 
Table 3

Alternative Pathways for Competence

\begin{tabular}{ll}
\hline Pathway & Description \\
\hline Initial experience* & $\bullet$ Level 2 or 3 CCT trained \\
& OR \\
& $\bullet 4$ weeks of dedicated time with a qualified practitioner of vascular CT \\
& $\bullet$ Level 2 or 3 CCT trained \\
& OR \\
& $\bullet 4$ weeks of additional equivalent experience through supervised time, CME, other courses, case \\
& studies, CD/DVD training \\
& $\bullet$ Mentored interpretation of 50 cases of vascular CT, ideally covering a broad range of vascular beds \\
& $\bullet 100$ cases of vascular CT from teaching files, case studies, CDs/DVDs, CME courses \\
Minimum number of mentored exams & \\
Additional case reviews & *
\end{tabular}


Table 4

CMR Hardware

\begin{tabular}{ll}
\hline CMR Hardware & Details \\
\hline Magnet & $\begin{array}{l}\text { Superconducting magnet with homogenous magnetic field (1.5 T or 3.0 T) } \\
\text { Wradient coils }\end{array}$ \\
$\begin{array}{l}\text { Within the bore of the magnet. Current-carrying coil which generates a highly linear magnetic field gradient along a } \\
\text { particular direction (so that the magnetic field will be stronger in some locations than others). Helps produce images. }\end{array}$ \\
$\begin{array}{l}\text { Radiofrequency coils } \\
\text { Single or multiple loops of electrical conductor (e.g., wire, tubing) designed to produce a magnetic field from current } \\
\text { flowing in the conductor or to detect a voltage induced in the conductor by a changing magnetic field. }\end{array}$ \\
Receiver coils & Measures MR signal at the resonance frequency so that the MR image can be produced. \\
\hline CMR = computed magnetic resonance; MR = magnetic resonance; $\mathrm{T}=$ Tesla.
\end{tabular}


Table 5

\section{Cognitive Skills Required for Competence in Vascular MR}

\begin{tabular}{|c|c|}
\hline Knowledge & Cognitive Skills Required \\
\hline \multirow[t]{5}{*}{ General } & Hardware and physical principles of MR \\
\hline & Scanning principles and scanning modes for noncontrast- and contrast-enhanced vascular imaging \\
\hline & Principles of intravenous contrast administration for optimal vascular imaging \\
\hline & Principles of image post-processing and appropriate applications \\
\hline & Safety issues surrounding MR, including contraindications \\
\hline \multirow[t]{2}{*}{ Vascular anatomy } & $\begin{array}{l}\text { Normal anatomy of the aorta, brachiocephalic, cerebrovascular, pelvic and lower extremity, renal, and } \\
\text { mesenteric arteries }\end{array}$ \\
\hline & $\begin{array}{l}\text { Normal anatomy of the SVC and IVC, cerebrovascular, pelvic, lower extremity, renal, and mesenteric } \\
\text { veins }\end{array}$ \\
\hline \multirow[t]{2}{*}{ Vascular pathology } & $\begin{array}{l}\text { Congenital anomalies, aneurysm, dissection, occlusion, and stenosis) of the aorta, brachiocephalic, } \\
\text { cerebrovascular, pelvic and lower extremity, renal, and mesenteric arteries }\end{array}$ \\
\hline & $\begin{array}{l}\text { Thrombosis, compression, and occlusion of the superior and inferior vena cava, cerebrovascular, pelvic, } \\
\text { lower extremity, renal, and mesenteric veins }\end{array}$ \\
\hline \multicolumn{2}{|c|}{$\begin{array}{l}\text { Symptoms and signs of disease } \\
\text { related to the vascular pathology } \\
\text { listed above }\end{array}$} \\
\hline
\end{tabular}

$\mathrm{IVC}=$ inferior vena cava; $\mathrm{MR}=$ magnetic resonance $\mathrm{SVC}=$ superior vena cava. 
Table 6

Alternative Pathways for Competence in Vascular MR

\begin{tabular}{|c|c|}
\hline Pathway & Description \\
\hline \multirow[t]{6}{*}{ Initial experience ${ }^{*}$} & - Level 2 or 3 CMR trained \\
\hline & OR \\
\hline & - 4 weeks of dedicated time with a qualified practitioner of vascular MR \\
\hline & - Level 2 or 3 CMR trained \\
\hline & OR \\
\hline & $\begin{array}{l}\text { - } 4 \text { weeks of additional equivalent experience through supervised time, CME, other courses, case } \\
\text { studies, CD/DVD training }\end{array}$ \\
\hline Minimum number of mentored exams & - Mentored interpretation of 50 cases of vascular MR, ideally covering a broad range of vascular beds \\
\hline Additional case reviews & - 100 cases from teaching files, case studies, CDs/DVDs, CME courses \\
\hline
\end{tabular}

